\title{
Surgical Treatment of Rectal Prolapse
}

\author{
Eung Jin Shin \\ Department of Surgery, Soonchunhyang University Bucheon Hospital, Bucheon, Korea
}

Rectal prolapse is defined as a protrusion of the rectum beyond the anus. Although rectal prolapse was recognized as early as $1500 \mathrm{BC}$, the optimal surgical procedure is still debated. The varied operative procedures available for treating rectal prolapsed can be confusing. The aim of treatment is to control the prolapse, restore continence, and prevent constipation or impaired evacuation. In elderly and high-risk patients, perineal approaches, such as Delorme's operation and Altemeier's operation, have been preferred, although the incidence of recurrence and the rate of persistent incontinence seem to be high when compared with transabdominal procedures. Abdominal operations involve dissection and fixation of the rectum and may include a rectosigmoid resection. From the late twentieth century, the laparoscopic procedure has been applied to the treatment of rectal prolapse. Current laparoscopic surgical techniques include suture rectopexy, stapled rectopexy, posterior mesh rectopexy with artificial material, and resection of the sigmoid colon with colorectal anastomosis with or without rectopexy. The choice of surgery depends on the status of the patient and the surgeon's preference.

Keywords: Rectal prolapse; Procidentia; Rectopexy; Laparoscopy

\section{INTRODUCTION}

Rectal prolapse describes a condition in which the entire layer of the rectal wall protrudes through the anal canal. It is more commonly found in elderly women. Rectal prolapse is classified into two types: complete or full-thickness prolapse and incomplete or partial thickness prolapse. Complete prolapse represents a protrusion of the entire layer of the rectum to the outside of the anus and, thus, shows concentric folds. Incomplete prolapse is defined as a condition in which the protruding rectal wall is limited to the inside of the anal canal, which is also referred to as occult rectal prolapse or internal rectal intussusception. In clinical practice, mucosal prolapse is readily confused with rectal prolapse. Mucosal prolapse is not a protrusion of the whole layer of the rectal wall, but a portion of the rectal wall or only the anal mucosa. It should be differentiated from rectal prolapse

Received: July 6, 2010 Accepted: August 6, 2010

Correspondence to: Eung Jin Shin, M.D.

Department of Surgery, Soonchunhyang University Bucheon Hospital,

1174 Jung 1-dong, Wonmi-gu, Bucheon 420-767, Korea

Tel: +82-32-621-5249, Fax: +82-32-621-5018

E-mail: colon@schmc.ac.kr

(C) 2011 The Korean Society of Coloproctology

This is an open-access article distributed under the terms of the Creative Commons Attribution NonCommercial License (http://creativecommons.org/licenses/by-nc/3.0) which permits unrestricted noncommercial use, distribution, and reproduction in any medium, provided the original work is properly cited. as the surgical treatments are different.

Historically, rectal prolapse was described on papyrus in 1500 BC [1]. Hippocrates described treatment for rectal prolapse: the patients could be treated by hanging them to a tree upside down, applying sodium hydroxide to the mucosa, and fixing for 3 days. In medieval times, other treatments were suggested; rectal prolapse could be prevented by using a scar obtained through burning the anus or by using a stick. In the 20th century, rectal prolapse was studied scientifically; nonetheless, the etiology and the treatment methods have not yet been established clearly. To date, there are various surgical treatments for rectal prolapse (Table 1). In this article, the author will mainly focus on current surgical treatments for rectal prolapse.

\section{ETIOLOGY}

In 1912, Moschowitz [2] observed that the anterior rectovaginal pouch was abnormally deep in patients with rectal prolapse and suggested the theory of a sliding hernia in which the anterior rectal wall is herniated to the defect of the pelvic fascia. Thus, repair of the defect in the levator ani muscle and closure of Douglas pouch were proposed as its treatment. However, this method resulted in high recurrence rates; thus, it is not used in clinics anymore.

In 1968, Broden and Snallmann [3] demonstrated that rectal intussusception is the cause of rectal prolapse by the use of cine- 
Table 1. Surgical procedure for rectal prolapse

\begin{tabular}{lll}
\hline & \multicolumn{1}{c}{ Author (year) } & \multicolumn{1}{c}{ Procedure } \\
\hline $\begin{array}{l}\text { Transabdominal } \\
\text { Pelvic floor reconstruction }\end{array}$ & Moschcowitz (1212) & Douglas closure \\
& Graham (1942) & Anterior levatoropexy \\
& Goligher (1970) & $\begin{array}{l}\text { Anterior \& posterior } \\
\text { levatoropexy }\end{array}$ \\
& Sullivan (1990) & Total pelvic mesh repair \\
Anterior fixation & Pemberton (1937) & Sigmoidopexy \\
& Ripstein (1952) & Anterior Teflon sling \\
& Nigro (1958) & Ventral Teflon sling \\
\hline Posterior fixation & Wells (1959) & Ivalon sling \\
& Sudeck (1923) & Suture rectopexy \\
Resection & Muir (1962) & Anterior resection \\
& Frykman (1969) & Sigmoid resection \& \\
& rectopexy \\
\hline Perineal & Parks (1975) & Posterior anal repair \\
& Thiersch (1981) & Perineal sling \\
& Delorme (1964) & Transanal repair \\
& Altemeier (1971) & Rectosigmoidectomy \\
& Thomas (1975) & Suture rectopexy \\
\hline & &
\end{tabular}

defecography. In 1970, Theuerkauf et al. [4] confirmed this theory by using radiographs taken after applying radioisotopes to the rectal mucosa. The theory of rectal intussusception is that the rectal mucosa, $6-8 \mathrm{~cm}$ from the anal verge, becomes the leading point, and intussusception is developed. Intussusception is aggrevated by excessive straining for a long time and becomes an apparent rectal prolapse. This is supported by the observation that the internal rectal pressure in patients with rectal prolapse is lower than normal. To date, the theory of rectal intussusception has been widely accepted, but controversies still exist. Shorvon et al. [5] reported that more than $50 \%$ of normal individuals have intussusception on cinedefecography. Mellgren et al. [6] proposed that not all patients with rectal intussusception would eventually develop rectal prolapse.

In addition, Parks et al. [7] suggested the theory of perineal nerve injury. In 1977, they performed biopsies of the pelvic floor in patients undergoing posterior repair for fecal incontinence and rectal prolapse, and confirmed injury of the perineal nerve histologically. They explained that the cause of rectal prolapse was a weakening of the pelvic floor muscles due to injury of the perineal nerve. Perineal nerve injury also causes fecal incontinence. Possible reasons for nerve injury are descent of the pelvic floor, vaginal delivery, or excessive straining during defecation. In patients with rectal prolapse who do not have incontinence, there is no evidence of pudendal nerve injury on the anal sphincter electromyogram. Thus, it appears that this theory is applicable only to rectal prolapse patients with fecal incontinence. In addition, the relaxation of the lateral ligaments and the inertia of the pelvic floor muscles have been suggested as other causes for rectal prolapse [8].

\section{CLINICAL FEATURES AND DIAGNOSIS}

The most frequent symptoms are protrusion, hemorrhage, frequent bowel movement, and tenesmus. In the early phase, the protrusion is shown only during defecation, and with time, the protrusion becomes more frequent and severe. Symptoms, such as coughing or sneezing, are induced during increased abdominal pressure. Other common symptoms are fecal incontinence and mucous discharge through the anus. In most patients, decreased resting rectal pressure and relaxation of the anal sphincter cause the mucous discharge. Hemorrhage occurs frequently in cases in which the prolapsed rectum is left unreduced. If severe hemorrhage or strangulation is detected, emergency treatments should be administered. If rectal prolapse is persistent for a long time, urological impairments, such as bladder stones or urethral stricture, may be associated. Disorders of the pelvic floor, such as bladder prolapse or uterine prolapse, may also be combined [9]. In such cases, treatments should be directed to not only rectal prolapse but also the disorders of the pelvic floor.

Rectal prolapse can be diagnosed readily in outpatient clinics by history taking and inspection of the protrusion shape. In cases of complete prolapsed, the rectal wall with mucosal congestion and edema is protruded to the anus by $8-15 \mathrm{~cm}$. In cases of incomplete prolapse or occult prolapse, cinedefecography is of help. The funnel-shaped rectum is separated from the sacrum and excessively fluctuates, and during straining, it forms a ringshaped pouch. In addition, in typical rectal prolapse cases, the long sigmoid colon and a deep pouch of Douglas are observed. Anorectal physiology tests, such as anal manometry, electromyography, or colonic transit time measurement, are also used.

\section{SURGICAL TREATMENTS}

The rectal prolapse can be completely corrected only by surgical treatment. Nonetheless, most patients are in old age, and general performance status is poor. Accordingly, during the acute phase, nonoperative treatments such as medications reducing edema, correction of constipation, exercises straining the perineum, electric simulation, injection of a sclerosing agent, or rubber band ligation are attempted. Biofeedback is of help to the functional recovery after surgery, but it is not suitable as the primary treatment [10].

Surgical procedures for rectal prolapse are diverse. Nevertheless, the ultimate goal of treatment is to prevent prolapse, to restore defecation function, and to prevent constipation or incontinence. For such purposes, extensive bowl dissection or fixation is required, and to this end, surgery by using the abdominal ap- 
proach or the perineal approach is essential. Therefore, surgical methods are largely divided into abdominal approaches and perineal approaches. Representative surgical procedures are as follows:

\section{Perineal approach}

In the early 20th century, surgery through the perineum was the main stream. In 1891, Thiersch in Germany suggested an encirclement procedure in which a prosthesis was inserted around the anus, narrowing the anal opening. In 1900, Delorme in France reported a method that resected the rectal mucosa as a column shape and performed plication of the muscular layer. The perineal sigmoid colon-rectal resection was reported for the first time in 1889 by Mickulicz and was subsequently reported by Miles in 1933 and by Gabriel et al. in 1948; it became known widely in 1971 due to Altemeier [11]. The outcome of the perineal approach is shown in Table 2.

\section{Thiersch procedure}

This procedure is performed frequently in patients with old age or high risks. It is a simple procedure using a prothesis that narrows the anus. It can be performed under local anesthesia, and the patient's satisfaction is relatively high. When it was reported for the first time by Thiersch [12], a silver wire was used as a prosthesis. Presently, because of ulcers and other complications, instead of wires, sutures and nylon, dacron, silastic, teflon, and silicon rubber materials are used. If the anal opening is too narrow, fecal impaction may develop. After surgery, wound infection is relatively common, and if the infections become evident, the prothesis should be removed. After wound healing, the prothesis may be reinserted. Since it is performed selectively in the high risk group, results from long-term follow-ups are rare, and the recurrence rates in the literature are approximately $30-50 \%$ [13-16].

Table 2. Results after perineal procedure

\begin{tabular}{lccccc}
\hline Author & Year & Procedure & Patients & $\begin{array}{c}\text { Recurrence } \\
(\%)\end{array}$ & $\begin{array}{c}\text { Mortality } \\
(\%)\end{array}$ \\
\hline Oliver & 1994 & Delorme & 41 & 8.0 & 1.0 \\
Lechaux & 1995 & Delorme & 85 & 11.0 & 1.0 \\
Pescatori & 1998 & Delorme & 33 & 4.0 & 0 \\
Liberman & 2000 & Delorme & 34 & 0 & 0 \\
Byun & 2000 & Delorme & 29 & 3.4 & 0 \\
Watkins & 2003 & Delorme & 52 & 10.0 & 0 \\
Altemeier & 1971 & Altemeier & 106 & 3.0 & 0 \\
Prasad & 1986 & Altemeier & 25 & 0 & 0 \\
Williams & 1992 & Altemeier & 56 & 6.0 & 0 \\
Ramanujam & 1994 & Altemeier & 72 & 4.0 & 0 \\
Kim & 1999 & Altemeier & 183 & 29.0 & 0 \\
Kimmins & 2001 & Altemeier & 63 & 6.4 & 0 \\
\hline
\end{tabular}

Recently, instead of the Thiersch procedure alone, it is performed in combination with another perineal approach in most cases.

\section{Delorme procedure}

The Delorme procedure peels off the excessively herniated rectal mucosa, plicates the exposed rectal muscular layer, and sutures the anorectal mucosa [17]. As complications, hemorrhage, hematoma, wound dehiscence, and stenosis have been reported. Mortality is $0-4 \%$, and the recurrence rate is $4-38 \%$ [18-23]. After surgery, since the rectum is not fixed to the sacrum, a high recurrence rate, compared to other procedures, has been reported. Since this procedure is not involve entering the abdominal cavity, it can be performed relatively safely; thus, it can be applied to elderly high risk patients. The functional outcome of the plicated muscular ring to control defecation is still controversial. One of the reasons for recurrence is insufficient resection of the rectal mucosa, but there is no concensus regarding the optimal resection length of the mucosa. Many surgeons describe it as the area, by experience that it is no longer herniated and in which tension is felt when the resected mucosa is pulled. Nevertheless, this is not objective and is, thus, greatly confusing. For complete rectal prolapse cases, the author generally resected $15-20 \mathrm{~cm}$.

\section{Perineal sigmoid colon-rectal resection (Altemeier procedure)}

The perineal procedure is preferred in the United States and Europe. The protruded rectum is resected $2 \mathrm{~cm}$ above the dentate line, and the mesentery of the sigmoid colon is pulled sufficiently, ligated, and resected. Hand-sewn or stapled Anastomosis is carried out. To prevent fecal incontinence, an anterior levatoplasty is performed simultaneously. The rate of complications is lower than $10 \%$, and hemorrhage in the suture line is the most frequent complication. Although rare, pelvic abscess due to suture failure may develop. Altemeier [24] reported recurrence in 3 patients out of 106 patients. In the literature, however, the recurrence rate is reported to be $16-30 \%$ [25-28]. In Korea, in 1998, Rhyu et al. [29] reported a recurrence rate of $20 \%$ in 16 patients. Depending on the surgeon, when levatorplasty was performed simultaneously, the recurrence rate was reported to be lower than $10 \%$ in 3-year follow-up observations [30]. When the rectal prlapse recurred, it could be resected by using the same method [31] However, Corman [11] recommended the abdominal approach for treating recurrent prolapse because of the risk of ischemia in the distal rectum.

\section{Gant-Miwa procedure}

In the 1920s, Gant reported the plication procedure for a herniated rectal mucosa for the first time, but it was not widely accepted. Therefore, results of this procedure are rarely found in the English literature. In 1960, the Japanese surgeon Miwa introduced a procedure to perform the plication procedure and the Thiersch procedure simultaneously, and it became the most popular procedure for rectal prolapse in Japan [11]. Using a 3-0 
absorbable suture, the herniated mucosa was plicated by ligating the mucosa, the muscle layer was sutured 20-40 times as a bean-shape, and the anal opening was narrowed by using a prosthesis. To prevent a mucosal ulcer, a 5-mm ligation interval was recommended. In 2003, Yamana and Iwadare [32] reported Japanese data indicating that without significant complications, the recurrence rate was $23 \%$ and the patients satisfaction was $81.3 \%$. In Korea, there are some reports of this procedure. Lim et al. [33] reported a $6 \%$ recurrence rate in 50 cases. Kim et al. [34] reported a modified procedure in which levatoplasty was performed for the posterior rectal wall and the Gant-Miwa procedure was performed simultaneously for the anterior area.

\begin{abstract}
Abdominal approach
The perineal approach is a conservative procedure to resect or remove the herniated area in patients with high operative risk. On the other hand, the abdominal approach is a more aggressive and radical procedure through laparatomy or laparascopy. The abdominal procedure mainly involves extensive bowel dissection and fixation; thus, the type of surgical procedure is classified according to the method or the location of bowel fixation. The representative abdominal procedures are as follows:
\end{abstract}

\section{Rectopexy}

\section{- Suture rectopexy}

Suture rectopexy reported by Cutait in 1959 is the simplest method among abdominal approach procedures [35]. This is a method to pull the rectum sufficiently and to fix it to the sacrum or the fascia by using a non-absorbable suture. The principle is that after suturing, fibrosis and adhesion occur; thus, the rectum is fixated. The recurrence rate is approximately $3(0-$ $27 \%$ ) [36-38]. Fecal incontinence is improved in most cases, but the outcomes for constipation are controversial.

\section{- Prosthetic rectopexy}

Based on the principle of rectopexy by adhesion and fibrosis, on the assumption that the fixation using a mesh would be more effective than that using asimple suture, meshes and other prostheses have been developed. Materials such as fascia lata, nylon, polypropylene, marlex, polyvinylalchol, and polytape are used.

Table 3. Results after Ripstein procedure

\begin{tabular}{lcccc}
\hline Author & Year & Patients & $\begin{array}{c}\text { Recurrence } \\
(\%)\end{array}$ & $\begin{array}{c}\text { Mortality } \\
(\%)\end{array}$ \\
\hline Holmstrom & 1986 & 108 & 4.0 & 2.8 \\
Roberts & 1988 & 135 & 10.0 & 0.6 \\
Winde & 1993 & 47 & 0 & 0 \\
Tjandra & 1993 & 142 & 7.0 & 0.7 \\
Schultz & 2000 & 69 & 2.0 & 0 \\
\hline
\end{tabular}

(1) Anterior sling rectopexy (Ripstein operation)

The Ripstein procedure was introduced in 1965, and it has been used widely in the Unites States. As sling materials, teflon, marlex, and goretex are used. The original Ripstein procedure mobilized the redundant rectum and pulled and suture a mesh 4-5 $\mathrm{cm}$ in width to the sacral bone and the anterior rectal wall at the S2-3 level. If the traction of the rectum is not sufficient, the likelihood of recurrence is high. In addition, if the area between the sacrum and the rectum is narrowed excessively, constipation develops. Thus, it is important to maintain a $1-2 \mathrm{~cm}$ space. A modified method is to fixate a mesh to the sacrum with sutures or staples and to expose a part of the anterior wall of the rectum. In the literature, the recurrence rate is $0-13 \%$, and mortality is $0-2.8 \%$ (Table 3) [39-44]. Intraoperative complications, such as hemorrhage and hematoma in the sacral venous plexus, have been reported and frequently develop in males with a narrow pelvic cavity. As late complications, rectal stricture is problematic. McMahan et al. [45] reported that rectal stricture could be prevented by using goretex and exposing a part of the anterior rectal wall by using a modified procedure.

\section{(2) Posterior prosthetic rectopexy}

Posterior prosthetic rectopexy is a procedure in which after the rectum is sufficiently mobilized, a prosthesis is inserted into the space between the sacrum and the posterior rectum and is sutured to the rectum and the sacrum. The use of an ivalon sponge, described by Wells [46] in 1959, is advocated in England. Nevertheless, the ivalon sponge has not been approved for this procedure in the Unites States; thus, there are no reports from North America. When severe fibrosis is induced by the prosthesis, the normal anorectal angle is restored. The recurrence rate is approximately $3 \%$, and mortality caused by pelvic sepsis is approximately 1-2\% (Table 4). The improvement of fecal incontinence is 3-40\% after surgery [47-51]. Recently, instead of a non-absorbable sponge, absorbable materials, such as vicryl or dexon, have been used. When absorbable materials are used, the recurrence

Table 4. Results after posterior mesh rectopexy

\begin{tabular}{lcclll}
\hline Author & Year & Patients & Mesh & $\begin{array}{c}\text { Recurrence } \\
(\%)\end{array}$ & $\begin{array}{c}\text { Mortality } \\
(\%)\end{array}$ \\
\hline Penfold & 1972 & 101 & Ivalon & 3.0 & 0 \\
Morgan & 1972 & 150 & Ivalon & 3.0 & 3.0 \\
Keighley & 1984 & 100 & Polypropylene & 0 & 0 \\
Luukkonen & 1992 & 15 & Dexon & 0 & 0 \\
Novell & 1994 & 31 & Ivalon & 3.0 & 0 \\
Scaglia & 1994 & 16 & Polypropylene & 0 & 0 \\
Yakut & 1998 & 48 & Polypropylene & 0 & 0 \\
Aitola & 1999 & 96 & Polypropylene & 6.0 & 1.0 \\
Mollen & 2000 & 18 & Teflon & 0 & NS \\
\hline
\end{tabular}

NS, not stated. 
rate is not higher, and complications, such as pelvic sepsis, are reported to be slightly lower [52]. Complications are mainly affected by the bowel has been resected rather than by the type of prosthetic material. When pelvic sepsis develops, the prosthesis should be removed.

\section{Resection and fixation}

Colectomy for the treatment of rectal prolapse is described due to the observation that, after a low anterior resection, the anastomosis adheres to the sacrum. The sigmoid colon-rectal resection removes the redundant sigmoid colon, which could prevent bowl strangulation and volvulus, as well as correct constipation, in some patients. In the literature, when fixating the rectum, the use of sutures is preferred to the use of a prosthesis. Postoperative mortality is $0-6.5 \%$, and the recurrence rate is $0-5 \%$ (Table 5) [53-56]. Since the bowel is resected, postoperative mortality is higher than it is in other procedures. Luukkonene et al. [55] compared bowel resection combined with rectopexy to rectopexy alon, and reported that the incidence of postoperative constipations was lower in the bowel resection in combination with rectopexy group.

In rectal dissection, excision of the lateral ligament is still con-

Table 5. Results after suture rectopexy with resection

\begin{tabular}{lcccc}
\hline Author & Year & Patients & Recurrence (\%) & Mortality (\%) \\
\hline Frykman & 1969 & 80 & 0 & NS \\
Watts & 1985 & 138 & 2.0 & 0 \\
Luukkonen & 1992 & 15 & 0 & 6.7 \\
Deen & 1994 & 10 & 0 & 0 \\
Huber & 1995 & 42 & 0 & 0 \\
Yakut & 1998 & 19 & 0 & 0 \\
Kim & 1999 & 176 & 5.0 & NS \\
\hline
\end{tabular}

NS, not stated. troversial. One group insists that the excision of the lateral ligament results in a low recurrence while another group insists that the excision of the ligament might deteriorate constipation due to pelvic autonomic nerve injury $[57,58]$. In the meta-analysis by Bachoo et al. [59], when the lateral ligament was excised, constipation was worsened after surgery although the incidence was quite low. Thus, considering the recurrence rate, they insisted that the excision of the lateral ligament was beneficial. However, a limitation of this analysis is that only 2 studies were included, which is not sufficient to draw a definitive conclusion. In recent years, preserving the lateral ligament has been advocated to improve the defecation function and to prevent constipation.

\section{Laparoscopic procedure}

The laparoscopic colectomy has been performed from the early 1990s. Currently, laparoscopic surgery for rectal prolapse has gained wide acceptance. The principles of this surgical procedure, such as fixation or resection, are similar to those of a laparotomy. Laparoscopic surgery has numerous advantages, such as early recovery, shorter hospital stay, earlier return to work, superior cosmetic results, and less postoperative pain. A commonly performed procedures is the fixation procedure, dissecting the posterior rectum and fixing it by a mesh, or sigmoid colectomy (Table 6). In many reports in the literature including meta-analyses, in comparison with a laparatomy, the operation time is longer by approximately 1 hour, hospital stay is shorter by 3.5 days, and recurrence rate as well as complications, are not very different [60-72]. In Korea, Yoon et al. [73] compared a laparascopic rectal fixation to a laparatomy in 37 patients and reported equivalent operative outcomes.

\section{Selection of procedures}

In patients with rectal prolapse, various factors should be considered. First, depending on the risk of surgery and anesthesia,

Table 6. Results after laparoscopic procedure

\begin{tabular}{|c|c|c|c|c|c|c|}
\hline Author & Year & Patients & Design & Procedure & Recurrence (\%) & Mortality (\%) \\
\hline Bruch & 1999 & 32 & Prospective & LSR & 0 & 0 \\
\hline Kessler & 1999 & 32 & Prospective & LSR & 6.0 & 0 \\
\hline Solomon & 2008 & 126 & Retrospective & LSR & 4.0 & 0 \\
\hline Yoon & 2002 & 26 & Retrospective & LSR & $<1$ & 0 \\
\hline Boccasanta & 1999 & 10 & Prospective & LPMR & 0 & 0 \\
\hline Zittel & 2000 & 29 & Prospective & LPMR & 4.0 & 0 \\
\hline Dulucq & 2007 & 77 & Prospective & LPMR & 1.0 & 0 \\
\hline Xynos & 1999 & 10 & Prospective & LARR & 0 & 0 \\
\hline Stevenson & 2005 & 117 & Prospective & LARR & 2.5 & $<1$ \\
\hline
\end{tabular}

LSR, laparoscopic suture rectopexy; LPMR, laparoscopic posterior mesh repair; LARR, laparoscopic resection-rectopexy; NS, not stated. 
either an abdominal approach or a perineal approach should be selected. Second, the functional aspects, such as fecal incontinence and constipation, should be considered carefully. The preference of the surgeon for one operative procedure over others is also important. The preference is different depending on the country and whether prosthestic materials are used. In the recent literature, an abdominal approach via laparoscopy is rapidly increasing in acceptance. The posterior prosthetic rectopexy is the preferred procedure, and in bowel resection cases, preservation of the lateral ligament is more beneficial for the defecation function. The perineal approach shows a higher recurrence rate than the abdominal approach; nonetheless, it can be performed safely in high risk patients. A perineal sigmoid colon-rectal resection (Altemeier procedure) shows the lowest recurrence rate and is performed widely while the Delorme procedure is performed selectively [74]. If the prolapsed bowel shows incarceration or necrosis, a perineal approach is preferred as an initial choice. For patients in whom the prolapse recurs after an initial perineal approach, reoperation via a perineal approach is feasible. Recently, the Altemeier procedure has been favored for healthy patients because of the shorter hospital stay and less invasiveness [75-77].

\section{CONCLUSION}

The surgical procedures for rectal prolapse are diverse, indicating that the precise etiology and treatment strategy have not been clearly established. If the best procedure is to be selected and favorable outcomes achieved, careful considerations of patient's information and surgeon's clinical experience are required. Unlike surgery for malignancy, the functional aspects, such as quality of life and defecation, should be considered carefully in surgery for rectal prolapse. Attention should be paid to multidimensional patient care, as well as surgical techniques. Particularly, rectal prolapse patients may have a uterine prolapse or a bladder prolapse; thus, a multidisciplinary team approach may also become important. For the best results, a considered plan prior to surgery, optimal surgery by an experienced hand and careful patient care are important.

\section{CONFLICT OF INTEREST}

No potential conflict of interest relevant to this article was reported.

\section{REFERENCES}

1. Ballantyne GH. The historical evolution of anatomic concepts of rectal prolapse. Semin Colon Rectal Surg 1991;2:170-9.

2. Moschowitz AV. The pathogenesis, anatomy and cure of prolapse of the rectum. Surg Gynecol Obstet 1912;15:7-21.

3. Broden B, Snellman B. Procidentia of the rectum studied with cineradiography: a contribution to the discussion of causative mecha- nism. Dis Colon Rectum 1968;11:330-47.

4. Theuerkauf FJ Jr, Beahrs OH, Hill JR. Rectal prolapsed: causation and surgical treatment. Ann Surg 1970;171:819-35.

5. Shorvon PJ, McHugh S, Diamant NE, Somers S, Stevenson GW. Defecography in normal volunteers: results and implications. Gut 1989;30:1737-49.

6. Mellgren A, Schultz I, Johansson C, Dolk A. Internal rectal intussusception seldom develops into total rectal prolapse. Dis Colon Rectum 1997;40:817-20.

7. Parks AG, Swash M, Urich H. Sphincter denervation in anorectal incontinence and rectal prolapse. Gut 1977;18:656-65.

8. Kuijpers HC. Treatment of complete rectal prolapse: to narrow, to wrap, to suspend, to fix, to encircle, to plicate or to resect? World J Surg 1992;16:826-30.

9. Altman D, Zetterstrom J, Schultz I, Nordenstam J, Hjern F, Lopez A, et al. Pelvic organ prolapse and urinary incontinence in women with surgically managed rectal prolapse: a population-based case-control study. Dis Colon Rectum 2006;49:28-35.

10. Hamalainen KJ, Raivio P, Antila S, Palmu A, Mecklin JP. Biofeedback therapy in rectal prolapse patients. Dis Colon Rectum 1996; 39:262-5.

11. Corman ML. Colon and rectal surgery. Philadelphia: Lippincott Williams \& Wilkins; 2005.

12. Thiersch C. Carl Thiersch 1822-1895. Concerning prolapse of the rectum with special emphasis on the operation by Thiersch. Dis Colon Rectum 1988;31:154-5.

13. Labow S, Rubin RJ, Hoexter B, Salvati EP. Perineal repair of rectal procidentia with an elastic fabric sling. Dis Colon Rectum 1980; 23:467-9.

14. Poole GV Jr, Pennell TC, Myers RT, Hightower F. Modified Thiersch operation for rectal prolapse. Technique and results. Am Surg 1985;51:226-9.

15. Earnshaw JJ, Hopkinson BR. Late results of silicone rubber perianal suture for rectal prolapse. Dis Colon Rectum 1987;30:86-8.

16. Hunt TM, Fraser IA, Maybury NK. Treatment of rectal prolapse by sphincteric support using silastic rods. Br J Surg 1985;72:491-2.

17. Classic articles in colonic and rectal surgery. Edmond Delorme 1847-1929. On the treatment of total prolapse of the rectum by excision of the rectal mucous membranes or recto-colic. Dis Colon Rectum 1985;28:544-53.

18. Senapati A, Nicholls RJ, Thomson JP, Phillips RK. Results of Delorme's procedure for rectal prolapse. Dis Colon Rectum 1994;37: 456-60.

19. Watts AM, Thompson MR. Evaluation of Delorme's procedure as a treatment for full-thickness rectal prolapse. Br J Surg 2000;87: 218-22.

20. Lechaux JP, Lechaux D, Perez M. Results of Delorme's procedure for rectal prolapsed: advantages of a modified technique. Dis Colon Rectum 1995;38:301-7.

21. Oliver GC, Vachon D, Eisenstat TE, Rubin RJ, Salvati EP. Delorme's procedure for complete rectal prolapse in severely debilitated patients: an analysis of 41 cases. Dis Colon Rectum 1994;37:461-7. 
22. Byun SW, Kim HS. Results of Delorme's procedure for rectal prolapse. J Korean Soc Coloproctol 2000;16:407-14.

23. Tobin SA, Scott IH. Delorme operation for rectal prolapse. Br J Surg 1994;81:1681-4.

24. Altemeier WA, Culbertson WR, Schowengerdt C, Hunt J. Nineteen years' experience with the one-stage perineal repair of rectal prolapse. Ann Surg 1971;173:993-1006.

25. Agachan F, Pfeifer J, Joo JS, Nogueras JJ, Weiss EG, Wexner SD. Results of perineal procedures for the treatment of rectal prolapse. Am Surg 1997;63:9-12.

26. Watts JD, Rothenberger DA, Buls JG, Goldberg SM, Nivatvongs S. The management of procidentia. 30 years' experience. Dis Colon Rectum 1985;28:96-102.

27. Williams JG, Rothenberger DA, Madoff RD, Goldberg SM. Treatment of rectal prolapse in the elderly by perineal rectosigmoidectomy. Dis Colon Rectum 1992;35:830-4.

28. Prasad ML, Pearl RK, Abcarian H, Orsay CP, Nelson RL. Perineal proctectomy, posterior rectopexy, and postanal levator repair for the treatment of rectal prolapse. Dis Colon Rectum 1986;29:547-52.

29. Rhyu PG, Baek MJ, Lee MS, Kim CH, Song OP, Cho MS. Treatment of rectal prolapse by a perineal rectosigmoidectomy. J Korean Surg Soc 1998;55:868-73.

30. Pikarsky AJ, Joo JS, Wexner SD, Weiss EG, Nogueras JJ, Agachan F, et al. Recurrent rectal prolapse: what is the next good option? Dis Colon Rectum 2000;43:1273-6.

31. Fengler SA, Pearl RK, Prasad ML, Orsay CP, Cintron JR, Hambrick $\mathrm{E}$, et al. Management of recurrent rectal prolapse. Dis Colon Rectum 1997;40:832-4.

32. Yamana T, Iwadare J. Mucosal plication (Gant-Miwa procedure) with anal encircling for rectal prolapsed: a review of the Japanese experience. Dis Colon Rectum 2003;46:S94-9.

33. Lim SW, Lee CH, Lee KR, Yoo CJ, Park SY, Kim HS, et al. Clinical analysis of Gant-Miwa operation with Thiersch wiring based on 50 cases of rectal prolapse. J Korean Soc Coloproctol 1996;12: 503-10.

34. Kim JD, Ye BK, Jo HJ, Oh NG. Transanal posterior anorectoplasty of rectal prolapse. J Korean Soc Coloproctol 2002;18:269-73.

35. Muir EG. The surgical treatment of severe rectal prolapse. Proc R Soc Med 1959;52(Suppl):104-5.

36. Novell JR, Osborne MJ, Winslet MC, Lewis AA. Prospective randomized trial of Ivalon sponge versus sutured rectopexy for fullthickness rectal prolapse. Br J Surg 1994;81:904-6.

37. Kim KY, Shin JH, Kim YS. A clinical analysis of rectal prolapse treated by presacral rectopexy. J Korean Soc Coloproctol 1991;7: 45-9.

38. Briel JW, Schouten WR, Boerma MO. Long-term results of suture rectopexy in patients with fecal incontinence associated with incomplete rectal prolapse. Dis Colon Rectum 1997;40:1228-32.

39. Holmstrom B, Broden G, Dolk A. Results of the Ripstein operation in the treatment of rectal prolapse and internal rectal procidentia. Dis Colon Rectum 1986;29:845-8.

40. Tjandra JJ, Fazio VW, Church JM, Milsom JW, Oakley JR, Lavery
IC. Ripstein procedure is an effective treatment for rectal prolapse without constipation. Dis Colon Rectum 1993;36:501-7.

41. Roberts PL, Schoetz DJ Jr, Coller JA, Veidenheimer MC. Ripstein procedure. Lahey Clinic experience: 1963-1985. Arch Surg 1988; 123:554-7.

42. Launer DP, Fazio VW, Weakley FL, Turnhull RB Jr, Jagelman DG, Lavery IC. The Ripstein procedure: a 16-year experience. Dis Colon Rectum 1982;25:41-5.

43. Schultz I, Mellgren A, Dolk A, Johansson C, Holmström B. Longterm results and functional outcome after Ripstein rectopexy. Dis Colon Rectum 2000;43:35-43.

44. Winde G, Reers B, Nottberg H, Berns T, Meyer J, Bünte H. Clinical and functional results of abdominal rectopexy with absorbable mesh-graft for treatment of complete rectal prolapse. Eur J Surg 1993;159:301-5.

45. McMahan JD, Ripstein CB. Rectal prolapsed: an update on the rectal sling procedure. Am Surg 1987;53:37-40.

46. Wells C. New operation for rectal prolapse. Proc R Soc Med 1959; 52:602-3.

47. Penfold JC, Hawley PR. Experiences of Ivalon-sponge implant for complete rectal prolapse at St. Mark's Hospital, 1960-70. Br J Surg 1972;59:846-8.

48. Morgan CN, Porter NH, Klugman DJ. Ivalon (polyvinyl alcohol) sponge in the repair of complete rectal prolapse. Br J Surg 1972; 59:841-6.

49. Keighley MR, Fielding JW, Alexander-Williams J. Results of Marlex mesh abdominal rectopexy for rectal prolapse in 100 consecutive patients. Br J Surg 1983;70:229-32.

50. Yakut M, Kaymakcioglu N, Simsek A, Tan A, Sen D. Surgical treatment of rectal prolapsed: a retrospective analysis of 94 cases. Int Surg 1998;83:53-5.

51. Aitola PT, Hiltunen KM, Matikainen MJ. Functional results of operative treatment of rectal prolapse over an 11-year period: emphasis on transabdominal approach. Dis Colon Rectum 1999;42: 655-60.

52. Ross AH, Thomson JP. Management of infection after prosthetic abdominal rectopexy (Wells' procedure). Br J Surg 1989;76:610-2.

53. Kim DS, Tsang CB, Wong WD, Lowry AC, Goldberg SM, Madoff $\mathrm{RD}$. Complete rectal prolapse: evolution of management and results. Dis Colon Rectum 1999;42:460-6.

54. Cirocco WC, Brown AC. Anterior resection for the treatment of rectal prolapse: a 20-year experience. Am Surg 1993;59:265-9.

55. Luukkonen P, Mikkonen U, Jarvinen H. Abdominal rectopexy with sigmoidectomy vs. rectopexy alone for rectal prolapse: a prospective, randomized study. Int J Colorectal Dis 1992;7:219-22.

56. Frykman HM, Goldberg SM. The surgical treatment of rectal procidentia. Surg Gynecol Obstet 1969;129:1225-30.

57. Mollen RM, Kuijpers JH, van Hoek F. Effects of rectal mobilization and lateral ligaments division on colonic and anorectal function. Dis Colon Rectum 2000;43:1283-7.

58. Speakman CT, Madden MV, Nicholls RJ, Kamm MA. Lateral ligament division during rectopexy causes constipation but prevents 
recurrence: results of a prospective randomized study. Br J Surg 1991;78:1431-3.

59. Bachoo P, Brazzelli M, Grant A. Surgery for complete rectal prolapse in adults. Cochrane Database Syst Rev 2000;(2):CD001758.

60. Kellokumpu IH, Vironen J, Scheinin T. Laparoscopic repair of rectal prolapse: a prospective study evaluating surgical outcome and changes in symptoms and bowel function. Surg Endosc 2000;14: 634-40.

61. Kessler H, Jerby BL, Milsom JW. Successful treatment of rectal prolapse by laparoscopic suture rectopexy. Surg Endosc 1999;13: 858-61.

62. Bruch HP, Herold A, Schiedeck T, Schwandner O. Laparoscopic surgery for rectal prolapse and outlet obstruction. Dis Colon Rectum 1999;42:1189-94.

63. Benoist S, Taffinder N, Gould S, Chang A, Darzi A. Functional results two years after laparoscopic rectopexy. Am J Surg 2001; 182:168-73.

64. Scaglia M, Fasth S, Hallgren T, Nordgren S, Oresland T, Hulten L. Abdominal rectopexy for rectal prolapse. Influence of surgical technique on functional outcome. Dis Colon Rectum 1994;37: 805-13.

65. Himpens J, Cadiere GB, Bruyns J, Vertruyen M. Laparoscopic rectopexy according to Wells. Surg Endosc 1999;13:139-41.

66. Boccasanta P, Venturi M, Reitano MC, Salamina G, Rosati R, Montorsi $\mathrm{M}$, et al. Laparotomic vs. laparoscopic rectopexy in complete rectal prolapse. Dig Surg 1999;16:415-9.

67. Zittel TT, Manncke K, Haug S, Schafer JF, Kreis ME, Becker HD, et al. Functional results after laparoscopic rectopexy for rectal prolapse. J Gastrointest Surg 2000;4:632-41.

68. Dulucq JL, Wintringer P, Mahajna A. Clinical and functional out- come of laparoscopic posterior rectopexy (Wells) for full-thickness rectal prolapsed: a prospective study. Surg Endosc 2007;21: 2226-30.

69. Purkayastha S, Tekkis P, Athanasiou T, Aziz O, Paraskevas P, Ziprin $\mathrm{P}$, et al. A comparison of open vs. laparoscopic abdominal rectopexy for full-thickness rectal prolapse: a meta-analysis. Dis Colon Rectum 2005;48:1930-40.

70. Solomon MJ, Young CJ, Eyers AA, Roberts RA. Randomized clinical trial of laparoscopic versus open abdominal rectopexy for rectal prolapse. Br J Surg 2002;89:35-9.

71. Ashari LH, Lumley JW, Stevenson AR, Stitz RW. Laparoscopically-assisted resection rectopexy for rectal prolapse: ten years' experience. Dis Colon Rectum 2005;48:982-7.

72. Xynos E, Chrysos E, Tsiaoussis J, Epanomeritakis E, Vassilakis JS. Resection rectopexy for rectal prolapse. The laparoscopic approach. Surg Endosc 1999;13:862-4.

73. Yoon SG, Kim KU, Noh KY, Lee JK, Kim KY. Laparoscopic suture rectopexy for rectal prolapse. J Korean Soc Coloproctol 2002;18: 89-94.

74. Jacobs LK, Lin YJ, Orkin BA. The best operation for rectal prolapse. Surg Clin North Am 1997;77:49-70.

75. Madiba TE, Baig MK, Wexner SD. Surgical management of rectal prolapse. Arch Surg 2005;140:63-73.

76. Schiedeck TH, Schwandner O, Scheele J, Farke S, Bruch HP. Rectal prolapse: which surgical option is appropriate? Langenbecks Arch Surg 2005;390:8-14.

77. Gourgiotis S, Baratsis S. Rectal prolapse. Int J Colorectal Dis 2007; 22:231-43. 